\title{
Ground-penetrating radar observations for estimating the vertical displacement of rotational landslides
}

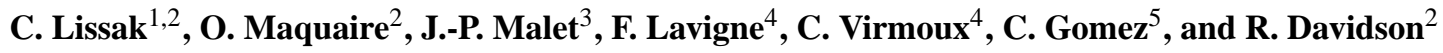 \\ ${ }^{1}$ PRODIG, CNRS - UMR8586, Université Paris Diderot, Sorbonne-Paris-Cité, Paris, France \\ ${ }^{2}$ Laboratoire LETG-CAEN GEOPHEN, Géographie Physique et Environnement, CNRS - UMR 6454, \\ Université de Caen-Basse-Normandie, Esplanade de la Paix, 14032 Caen CEDEX, France \\ ${ }^{3}$ Institut de Physique du Globe de Strasbourg, CNRS - UMR 7516, Ecole et Observatoire des Sciences de la Terre, \\ EOST/Université de Strasbourg, 5 rue Descartes, 67084 Strasbourg, France \\ ${ }^{4}$ Laboratoire de Géographie Physique, CNRS - UMR 8591, Meudon, France \\ ${ }^{5}$ University of Canterbury, Natural Hazards Research Centre, Waterways: Centre for Freshwater Management, \\ College of Sciences, Department of Geography, Private Bag 4800, 8140 Christchurch, New Zealand
}

Correspondence to: C. Lissak (candide.lissak@univ-paris-diderot.fr)

Received: 13 November 2014 - Published in Nat. Hazards Earth Syst. Sci. Discuss.: 12 December 2014 Revised: 31 May 2015 - Accepted: 02 June 2015 - Published: 30 June 2015

\begin{abstract}
The objective of this paper is to demonstrate the applicability of ground-penetrating radar (GPR) for monitoring the displacement of slow-moving landslides. GPR data are used to estimate the vertical movement of rotational slides in combination with other surveying techniques. The study area is located along the Normandy coast (northeast France) where several rotational landslides are continuously affected by a seasonal kinematic regime (low displacement rates of 0.01 to $0.10 \mathrm{~m} \mathrm{yr}^{-1}$ ) and periodically by major acceleration events (high displacement rates of 1.0 to $7.0 \mathrm{~m}$ per event).
\end{abstract}

\section{Introduction}

Slow-moving landslides can present highly variable displacement fields. Typically, rotational landslides are confined by a circular basal slip surface and are affected by high vertical component displacements at the head and high horizontal component displacements at the foot (Fig. 1). The direction and magnitude of the displacement components vary in space and time according to the bedrock geometry and the slope topography. In order to estimate the displacement rates at high accuracy (e.g. infra-centimetric), several geodetical ground-based techniques can be considered (Fig. 1) including global navigation satellite system (GNSS; Baldi et al.,
2008), high-precision topographic levelling (Coltorti et al., 1985) and total station surveys (Tsai et al., 2012). These techniques, however, provide variable precisions (Travelletti et al., 2012). Topographic levelling is the most accurate technique for measuring the displacement in the vertical component with precision of the order of $1 \mathrm{~mm}$. But this technique needs a direct visibility of the targets. The use of differential GNSS provides high-precision measurements of horizontal displacements according to the base station location and the satellite configuration (E-W and N-S components; Malet et al., 2002). However, in some landslide case studies, these classical investigation tools are not suitable or insufficiently precise because of difficult environmental conditions (dense vegetation, buildings), complex accessibility (private properties) or displacement rates are too small to measure. By reason of a good field configuration, to overcome some of these difficulties, ground-penetrating radar (GPR) was used to provide information on the vertical motion of ground structures over a period of several years. GPR observations allow mapping horizontal and vertical discontinuities and fractures at the sub-surface (Deparis et al., 2007). The tracking of these discontinuities using GPR provides an indirect measurement of the subsidence of the buried ground structures. Over the last decade, GPR observations have been frequently used in landslide research for identifying the geometry of the bedrock (Grandjean et al., 2000; Bichler et al., 2004; Sass et 


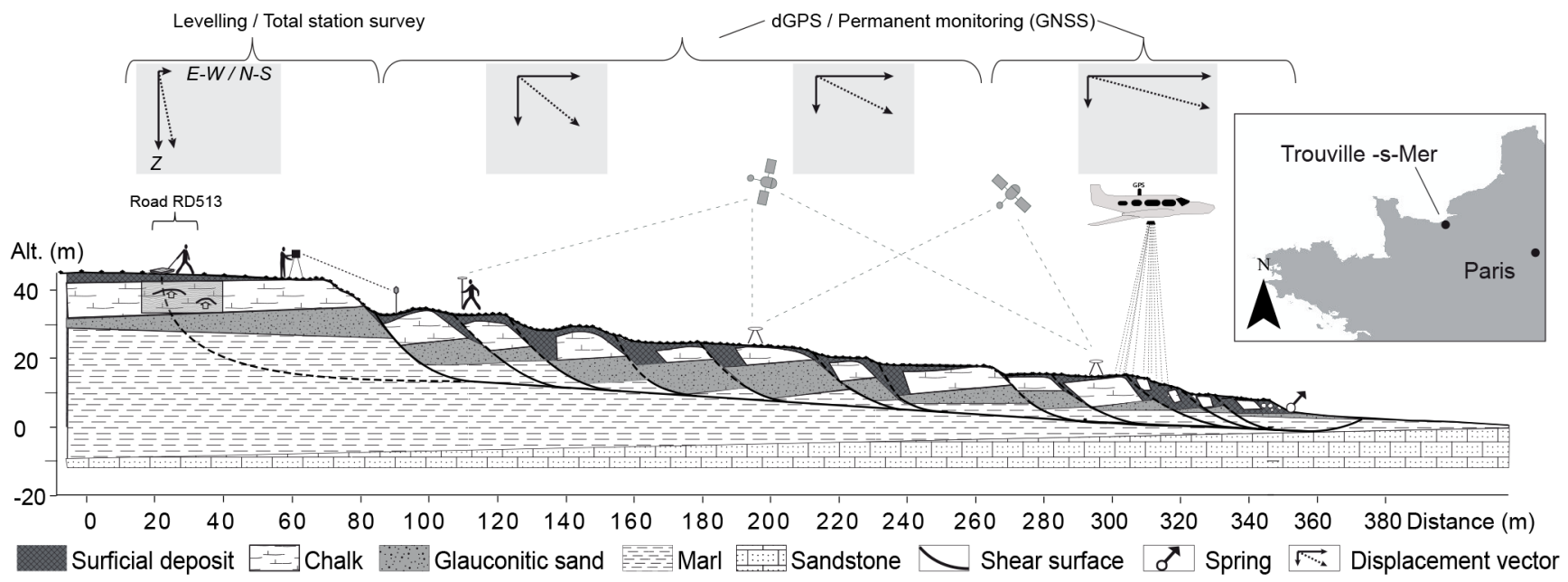

Figure 1. Typical cross section of a complex rotational landslide (example of the Cirque des Graves landslide) with indication on the distribution of displacement per unit from upslope to downslope and on the appropriate displacement monitoring techniques (location in Fig. 2a and b).

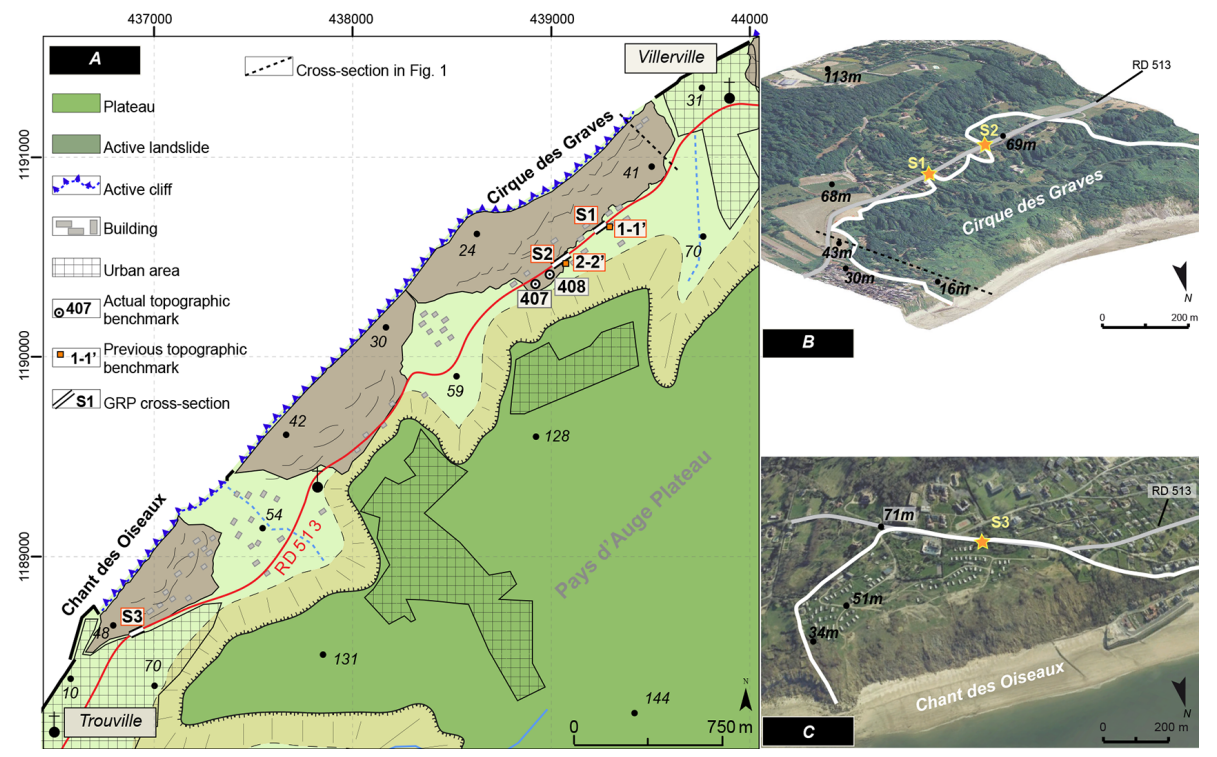

Figure 2. Morphology of the studied landslides. (a) Active landslides along the coast between Trouville and Villerville and location of the field investigations. (b) Aerial images 2006 of the Cirque des Graves landslide at Villerville. (c) Satellite view (Image $2014^{\circledR}$ Google Earth) of the Chant des Oiseaux landslide at Trouville.

al., 2008), characterizing the pattern of sub-surface fractures (Deparis et al., 2007), and estimating the layering of buried structures (Gutierrez et al., 2011; Carpentier et al., 2012). GPR observations are limited to the analysis of hard rocks and coarse or consolidated sediments because of the attenuation of the electromagnetic signal in clay-rich material and in saturated soils or with a high saline groundwater content (Annan, 2005; Jeannin et al., 2006).

In our experiment, GPR observations are used for monitoring the vertical displacement of the Cirque des Graves (Fig. 2b) and the Chant des Oiseaux (Fig. 2c) landslides
(Normandy coast, northwest France) for the period 1980 2010 (Ballais et al., 1984; Flageollet et al., 1987; Maquaire, 1990). The landslide motion is complex and associates a seasonal kinematic regime (subsidence of a few centimetres per year in springtime and autumn), an event-type kinematic regime, with high acceleration of displacements (several decimetres of subsidence per event), and deceleration periods (Lissak et al., 2014a). As a consequence of the seasonal activity and various acceleration events, several houses and road sections are continuously damaged or have been destroyed. Since the major reactivation in January 1982, the 
landslides have caused much damage along the main road (RD513). Many fissures and cracks appear every year on the road because of the seasonal activity of the landslides. These fissures are regularly filled and no monitoring network on the road exists today. Only a device of four fixed pylons was used to measure the road subsidence between 1982 and 1995. The multiple repairs of the road pavement have created a succession of road structures characterized by variation in soil density.

The evolution in time of this layering, which can be detected by GPR observations, is used in this study to infer the vertical displacement rates along this road. The structure of the road is adapted to a good GPR signal-to-noise ratio as it associates a foundation layer and a pavement layer with gravel and compacted sand.

In this paper, we illustrate how the GPR can be used as a complementary tool to traditional geodetic measurements for estimating vertical displacement rates along cross sections. We first detail the proposed methodology for detecting and locating the different road layers. Second, we interpret the position of the buried structures and quantify their displacement in time (for a period of 30 years). Finally, we compare the GPR-derived displacements to the displacements monitored at the surface with other surveying techniques.

\section{Study area}

The study area is located at the western margin of the sedimentary Paris Basin (northern France) in Normandy. On the edges of the Pays d'Auge plateau (Fig. 2a), in a coastal area below $140 \mathrm{~m}$ a.s.l., several active landslides occur. The two main unstable slopes are the Cirque des Graves landslide near Villerville village (Fig. 2a and b), which is the largest (47 ha; $\approx 20 \mathrm{~m}$ depth in 2012), most active and best documented landslide of the region (Maquaire, 1990; Lissak, 2012), and the Chant des Oiseaux landslide near Trouville city (Fig. 2a and c), which is smaller in size (20 ha, $\approx 20 \mathrm{~m}$ depth in 2012).

The Cirque des Graves and the Chant des Oiseaux landslides are located on low-elevation convex-concave slopes. At the toe of the uphill plateau, the slope range is 15 to $20 \%$. The landslides represent a complex morphology with a succession of multiple and embedded rotational slumps (Fig. 1). Typical morphological features testifying the presence of circular slip surfaces are observed, such as scarps of various sizes (Fig. 2b and c), open fissures, small grabens and counter-slopes. The two landslides are delineated upslope by a head scarp (5-10 $\mathrm{m}$ high) cut in the chalk formation (Lissak et al., 2014b), and downslope by a rocky reef in the sandstone formation. From the bottom to the top, the lithostratigraphic profile consists in Jurassic sedimentary rocks with superimposed strata of almost $10 \mathrm{~m}$ thick sandstone (plunging gently to the south-east at $7^{\circ}$ ), marls ( $25 \mathrm{~m}$ thick), a layer of glauconitic sands ( $2-5 \mathrm{~m}$ thick) and chalk formation whose thickness can exceed $50 \mathrm{~m}$ on the plateau (Fig. 1).
The Cirque des Graves and the Chant des Oiseaux slopes are continuously active landslides with horizontal displacement rates in the range $1-10 \mathrm{~cm} \mathrm{yr}^{-1}$ on average. Investigations at the Cirque des Graves landslide have demonstrated the control of rainfall inputs and groundwater fluctuations on the magnitude of the displacements. The recent observations confirm that the seasonal kinematics with low amplitude of displacements is associated with low-intensity rainfall periods associated with a limited groundwater rise $(+1 \mathrm{~m})$. As a consequence of this slow movement, a continuous subsidence of the upper part of the landslides is observed (Lissak et al., 2014a) causing small deformation of the road pavements and yearly repairs (Fig. 3d and e). The landslide is also episodically affected by large acceleration events with a return period of over 6-7 years. Four major events are known at the Cirque des Graves landslide (January 1982, February 1988, March 1995 and March 2001). These events are associated with long-lasting rainfall periods (several months with particularly abundant winter rainfall amount) with a high groundwater water level elevation ( $+2 \mathrm{~m}$ above the annual mean level defined for the period 1976-2013). During these events, displacements of up to several decimetres and major changes of the slope topography (retrogression of the main scarp, creation of new secondary scarps) were observed (Fig. 3b).

\section{Methods}

\subsection{Displacement monitoring network}

After the Cirque des Graves landslide reactivation in January 1982 the authorities in charge of the road traffic installed in November 1982 a monitoring network on both sides of the RD513 to monitor the road subsidence. The network consisted of four fixed pylons (PT 1-1' at both sides of the cross section S1; PT 2-2' at both sides of the cross section S2; Fig. 2a). Until 1995, when the monitoring device was destroyed, the altitude of the pylons was measured every 6 months using total stations with a sub-centimetre accuracy.

For scientific research a geodetic network was implemented in the landslide body in 1984 and utilized until 1988 to measure the vertical and the horizontal components of the landslide velocity. A part of the 84 initial benchmarks are still on site today and ensure the long-term continuity of observations. This monitoring network was updated in 2009 and supplemented by new cemented benchmarks. The actual network consists of 24 benchmarks. Two benchmarks were installed at boundary of the landslide (no. 407, no. 408; Fig. 2a) close to the previous observation point PT 1-1'. The position was measured by dGPS campaigns (Trimble R5) four times per year until 2012. The protocol consisted in 15 min observation time at each benchmark using a real-time kinematic mode; the position accuracy is estimated at $0.7 \mathrm{~cm}$ for the 


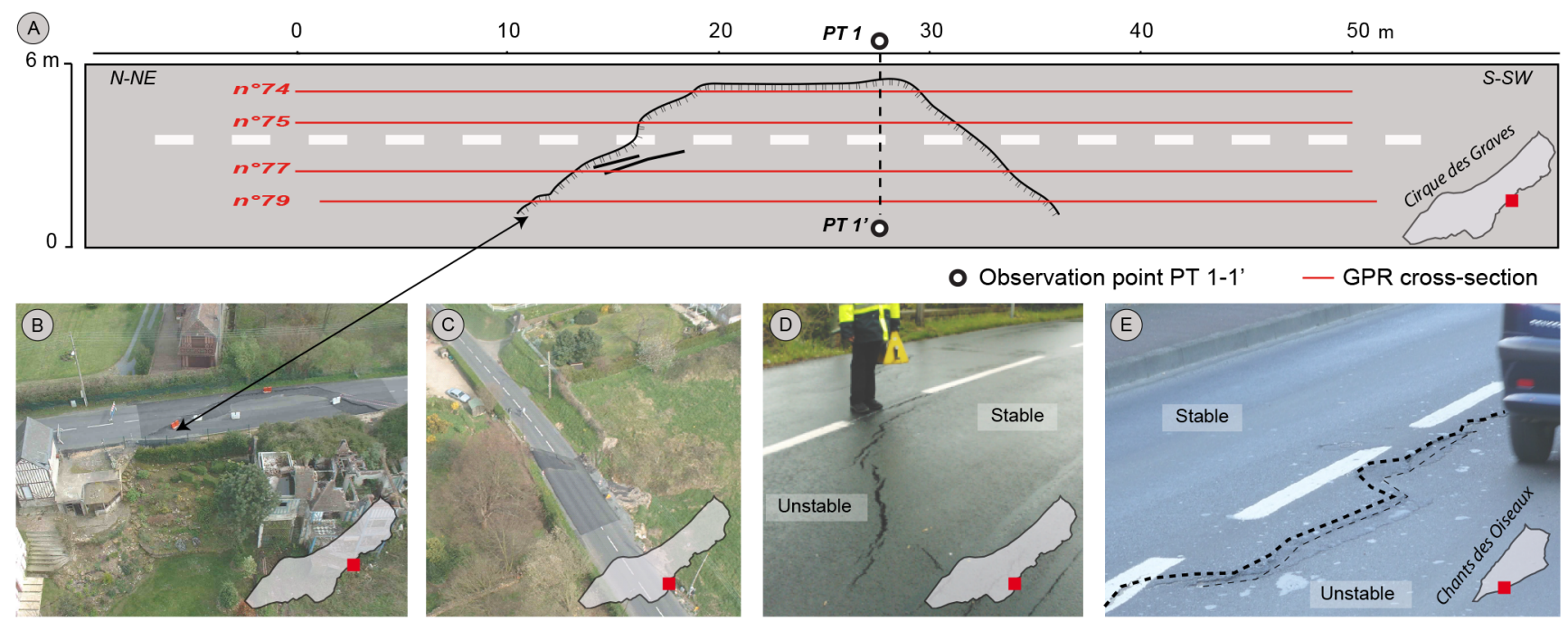

Figure 3. Damage observed along the RD513 road and strategy of GPR data acquisition. (a) Example of a GPR cross section plan (cross section S1) along the deformed road (multiple parallel profiles are acquired). (b) Oblique picture of the road collapse at the observation point S1 after the March 2001 event. (c) Oblique picture of the road collapse at the observation point S2 after the March 2001 failure. (d) Fissures observed along the road at point S2 in 2012. (e) Fissures along the road at the point S3 in 2009.

east component, $1.2 \mathrm{~cm}$ for the nort component, and $1.3 \mathrm{~cm}$ for the elevation.

Cracks and fissures that appear every year along the road are regularly filled and repaired by authorities. Consequently, it is impossible to install a permanent measuring device (e.g. fissurometer) on the road to precisely measure the subsidence of the road. Nevertheless, the widening is punctually measured during the winter season, just before they are repaired.

\subsection{GPR acquisition and processing}

For a non-invasive analysis of the subsurface, GPR measurements were acquired with a RAMAC GPR system (Mala Geoscience) along three cross sections (S1, S2, S3; Figs. 2a and 3) of 50-90 m length and $6 \mathrm{~m}$ wide along the road. To estimate the road's entire width, four to five parallel GPR profiles were acquired (Fig. 3a).

Considering the field configuration (trees, presence of clay-rich formation in depth, high water content), a shielded low-frequency antenna (dipole $500 \mathrm{MHz}$ in a monostatic arrangement) was used for an optimal image resolution around $10 \mathrm{~cm}$. With this configuration, the penetration depth does not exceed $4 \mathrm{~m}$ (Fig. 4). The GPR observations were recorded with an in-line sampling interval of $0.05 \mathrm{~m}$ and a total time window of $105 \mathrm{~ns}$. The GPR data were processed with the Reflex $^{\circledR}$ software (Sandmaier, 1997; Neal, 2004; Jol, 2009) with a time sampling of $9666 \mathrm{MHz}$ and a sampling rate of 1024. The processing chain consists of six steps. The inversion consists in the "Dewow" processing; this step 1 is usually realized to correct and remove the very lowfrequency components. The next step of processing, step 2, is the time gain process, using energy decay (factor 0.6). Then a correction of start time in step $3\left(T_{0}(z=0)\right)$ is applied to differentiate the air waves (which travels directly from the transmitter to the receiver in the air) and the ground waves in the soil surface. The data are then processed in step 1 using a band-pass Butterworth filter to improve the signal-to-noise ratio. The frequency bands chosen for filtering were $80-550 \mathrm{MHz}$. The topography effects are then corrected in step 5, by integrating the topographic profiles acquired by dGPS at several points along the cross sections. Finally, in step 6, a time-depth conversion is applied based on the diffraction hyperbola analysis. The constant is consequently estimated between 4 and 5. No velocity analysis was performed during the field campaign. The velocity analysis was grounded on the diffraction hyperbola. A specific velocity pattern was defined for each cross section, with a mean velocity of $0.15 \mathrm{~m} \mathrm{~s}^{-1}$ along the road. This result is explained by the specificities of the road structure (bitumen, gravel, sand, etc.).

\section{Results}

The surface displacements are analysed by combining GPR observations (Fig. 5) and surface geodetic measurements (levelling of the former topographic network, dGPS acquisition on the actual benchmark network; Fig. 6). The combination of these data provides a quantification of the total subsidence of the road RD513 crossed by the landslides between 1982 and 2010. Through the definition of the road depth in 1982, we can also estimate values of the major slope fail- 

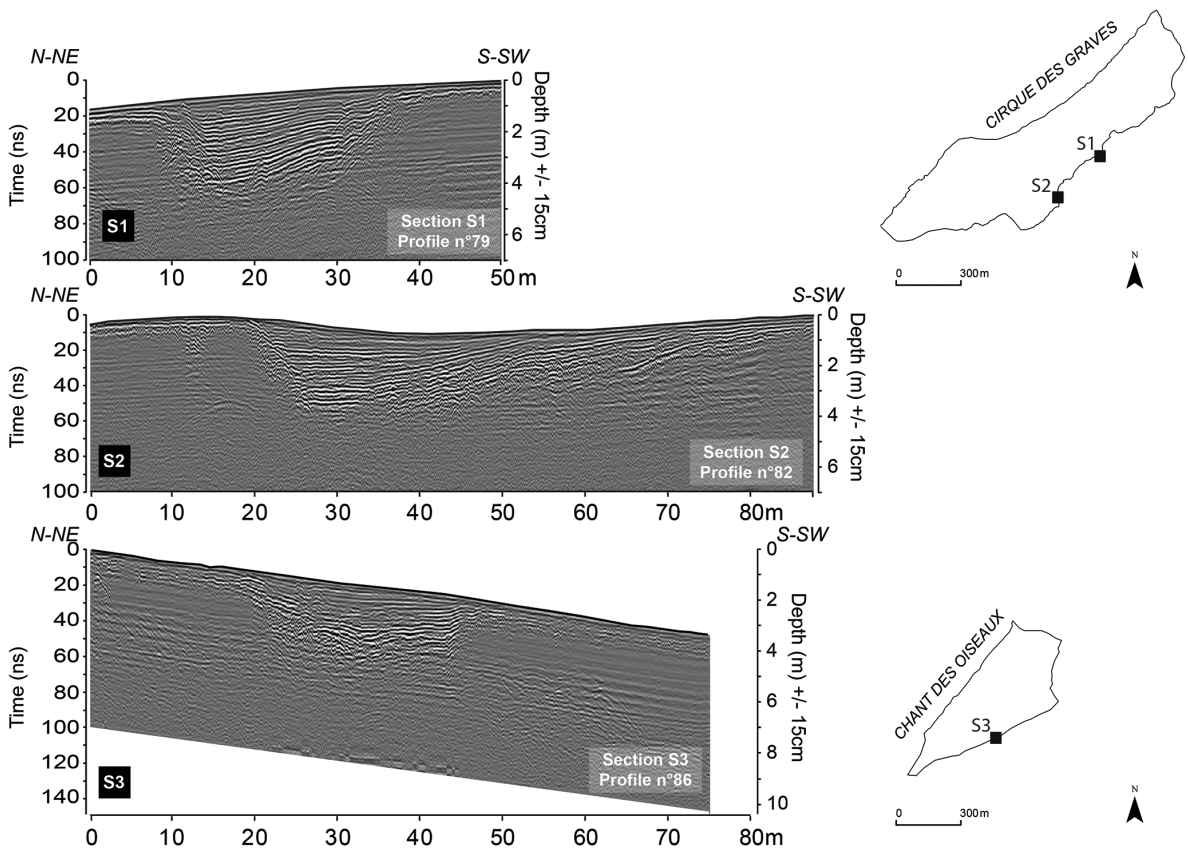

Figure 4. Radargram of cross sections S1 and S2 at the Cirque des Graves landslide and cross section S3 at the Chant des Oiseaux landslide.

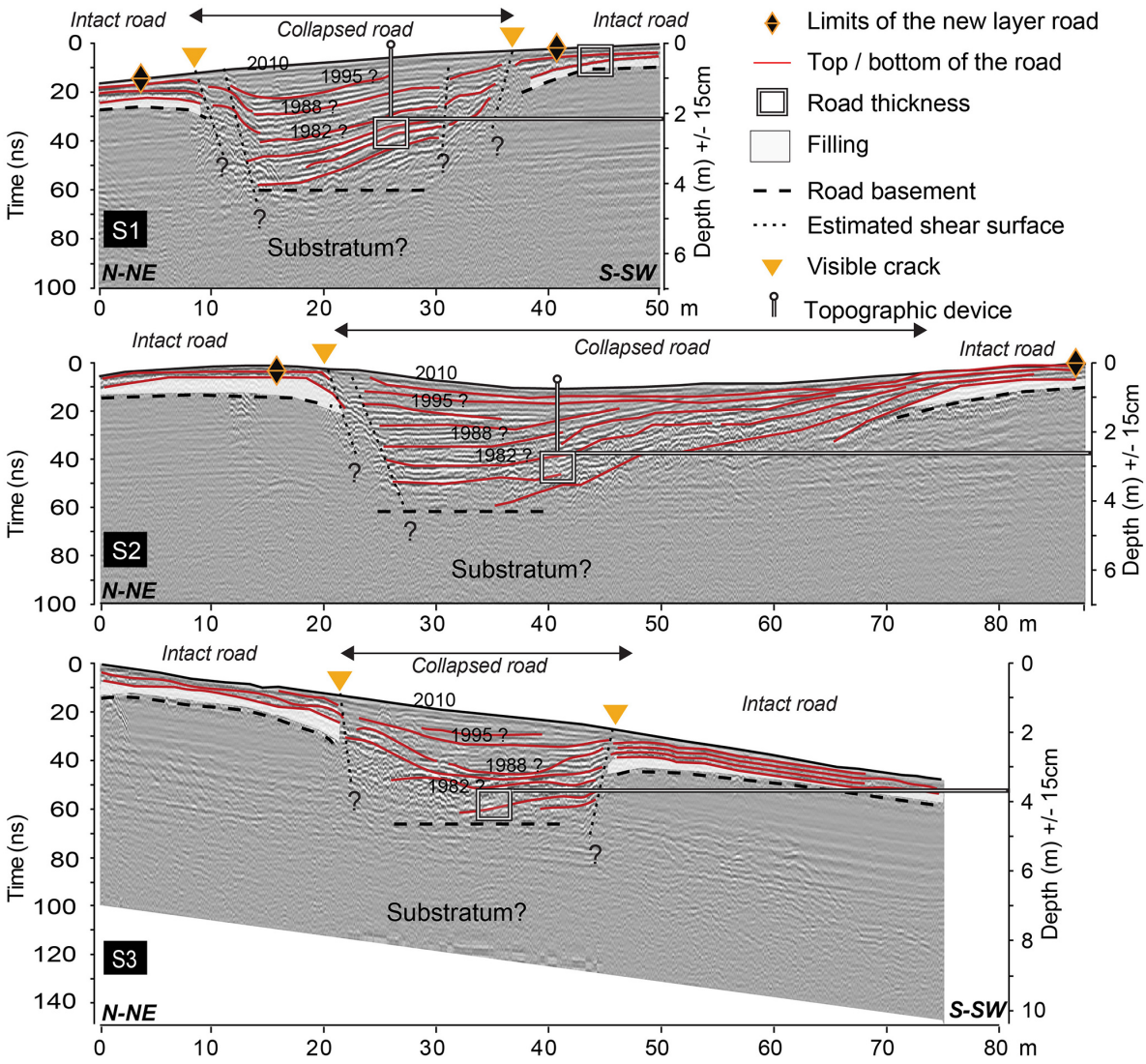

Figure 5. Interpretation of the ground-penetrating radar data for cross sections S1, S2 and S3. 
ure of January 1982, for which no direct measurements are available.

\subsection{Interpretation of the ground-penetrating radar cross sections}

The GPR observations allow detecting different soil structures at the subsurface with successive high-amplitude horizontal reflectors until depth of $4 \mathrm{~m}$ (Fig. 5). Then, until $6 \mathrm{~m}$ depth, the signal quality decreases. The horizontal reflectors can be interpreted as a significant contrast between two pavement layers. This distinction is probably related to a difference in the composition of the road structure or related to the presence of groundwater. The precision on the location in depth of the reflector is estimated at $15 \mathrm{~cm}$. No drilling was possible to confirm this hypothesis. But the road structure engineering plans were available to estimate the thickness of the pavement.

In cross section S1 (Fig. 5), the horizontal structure is bordered at the distances 10 and $37 \mathrm{~m}$ by a reflector dipping steeply. It corresponds to the boundaries of the landslide. In this part of the cross section, the number of detected layers increases with a thickening of the road structure. We can distinguish two units at the sub-surface: the intact road $(1 \mathrm{~m}$ thick) and the collapsed road (maximum $3 \mathrm{~m}$ thick). The collapsed road corresponds to the active zone that is affected by a continuous movement of subsidence. The growth fault with a concave upward fault plane bounds this area. The growth fault is characterized by a high updip angle and gradually flattens at its base into zone of detachment to become subhorizontal and sub-parallel to the recent pavement.

Assuming a road structure with a thickness of $1 \mathrm{~m}$ according to the engineering plans, we can differentiate the road pavement of 1982, 1988, 1995 and 2001 (corresponding to the actual road level). The top of the 1982 road is observed between 1.80 and $2.30 \mathrm{~m}$ depth depending on the initial topography. The top of the 1988 road is located between 1.40 and $2.0 \mathrm{~m}$ in depth; the top of the 1995 road is located between 1.0 and $1.40 \mathrm{~m}$ depth. Subsequently, after major acceleration events, the road pavement was completely reconstructed (i.e. excavation, new filling and bituminous surface). This pavement is almost $1 \mathrm{~m}$ thick according to engineering plans. After seasonal acceleration events, the road remediation consists of few centimetres of bitumen.

A similar structure is observed along cross section S2 (Fig. 5) located a few metres away. For this cross section, the horizontal structure is disturbed at $22 \mathrm{~m}$ by high-angle fault plans, and at $70 \mathrm{~m}$. The thickness of the collapsed road is asymmetric with a thickness of $4 \mathrm{~m}$ in the eastern part that progressively decreases westward. The level of the 1982 road is located at $3 \mathrm{~m}$ depth. The top of the 1988 road is at a maximum depth of $2.40 \mathrm{~m}$, and the top of the $1995 \mathrm{road}$ is at a maximum depth of $1.40 \mathrm{~m}$.

For the cross section S3 (Fig. 5), located at the Chant des Oiseaux landslide, this structure is also visible with a clear distinction between the intact road and the collapsed road. Between 22 and $47 \mathrm{~m}$ distance, the thickness of the road exceeds $3 \mathrm{~m}$. Little information on the landslide kinematic pattern was available for this landslide, as no major slope failure was precisely dated, but we can assimilate the behaviour of this landslide to the Cirque des Graves landslide, whose the road was partly reconstructed in 1982, 1988, 1995, and in 2001. We cannot define the year of the pavements for the Chant des Oiseaux radargrams. However, estimated subsidence values are quite similar for both landslides. Therefore, despite the absence of historical data for the Chant des Oiseaux landslide, we can assume that both landslides are characterized by almost the same slope dynamics with a comparable displacement pattern (high acceleration of displacements and a seasonal kinematic regime).

\subsection{Kinematics of the landslides over the period 1982-2010}

The depths of the different layers identified on the GPR cross sections are compared to the levelling data available for the period November 1982-April 1995. Figure 6 indicates a motion characterized by a constant displacement rate during 14 years and two major slope failures (February 1988, March 1995) with higher displacement rates. In between the two slope failures of May 1988 and April 1994, a subsidence of $0.25 \mathrm{~m}$ is measured at point PT 2-2', corresponding to a subsidence rate of $2-3 \mathrm{~cm} \mathrm{yr}^{-1}$. At the contrary, during the slope failures, $30-40 \mathrm{~cm}$ of collapse is reported (Lissak et al., 2013).

Between 2008 and 2012, during a period of low landslide activity, the landslide displacement was monitored by dGPS campaigns with a network of 24 benchmarks. In this paper, the results of only two benchmarks are presented. The 22 others are not close enough of the road. Their $x-y-z$ position was measured four times per year between 2009 and 2012 (Fig. 6). The vertical component of landslide movement is difficult to measure with dGPS because of the geometry of the satellite constellation (Malet et al., 2002). Consequently, the precision of the dGPS measurements is not sufficient to quantify accurately the displacement for $15 \mathrm{~min}$ short-period acquisitions. Nevertheless, the recent activity of the landslides is identifiable and can be punctually measured through the several fissures along the road, in winter season before being filled.

A subsidence rate of $1-2 \mathrm{~cm} \mathrm{yr}^{-1}$ is defined for the period 2008-2012. The combination of geophysical and geodetic surveying techniques provides an estimation of the total subsidence of the head of the landslide since January 1982. The results include the first reactivation of the Cirque des Graves landslide, for which no data were available before the GPR surveys. In this way, since January 1982, we can estimate a total collapse of the road comprised between 1.80 and $2.20 \mathrm{~m}$ at point PT 1-1', and between 2.40 and $2.60 \mathrm{~m}$ for point PT 2-2'. These results combine the values of the annual 


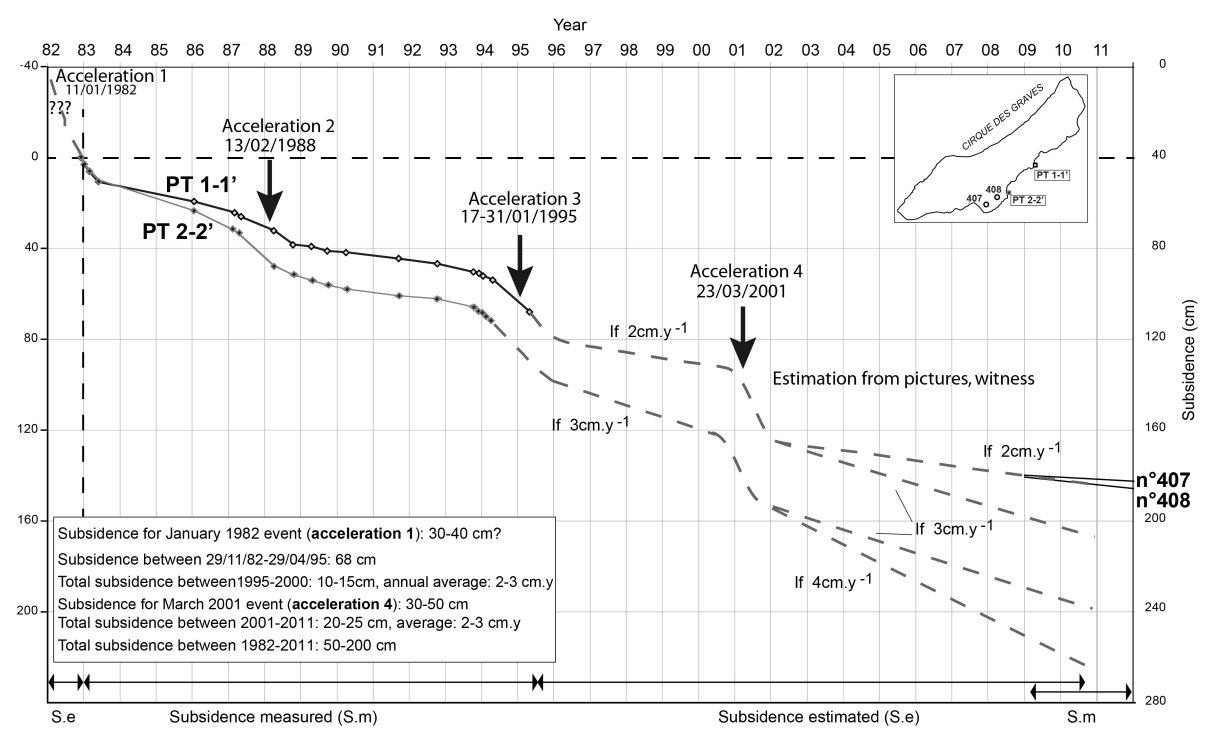

Figure 6. Subsidence of the road measured and estimated between 1982 and 2011.

subsidence of the road (estimated between 2 and $4 \mathrm{~cm} \mathrm{yr}^{-1}$ ) and the subsidence values of the four major accelerations (several decimetres per event). Prior to this study no subsidence value for the 1982 acceleration event was available. The assumed level of the road in $1982([1.80-2.20] \mathrm{m})$ provides data for the landslide head subsidence over the 1982 acceleration event $(30-40 \mathrm{~cm})$.

\section{Conclusions}

The use of the ground-penetrating radar observations for assessing slope dynamics is not very frequent. This technique is usually used to gain knowledge on the internal structures of the slope or to obtain some petrophysical properties of the discontinuities.

Indeed, in our application, the GPR observations were used to analyse the total subsidence of a road crossing two slow-moving landslides located along the Normandy coast. The observations also provided also valuable information on the dynamics of the landslide for the last 30 years. The geophysical surveys are complementary applied to surface displacement measurements. At the Cirque des Graves landslide, geodetic measurements were performed between 1982 and 1995 and between 2009 and 2012 to estimate the vertical component of the movement. The results indicate a total subsidence comprised between 1.8 and $4.0 \mathrm{~m}$ since 1982 for the two landslides. These results consider the seasonal pattern of the vertical movement associating a continuous subsidence rate of $2-4 \mathrm{~cm} \mathrm{yr}^{-1}$ and the four major slope failures characterized by several decimetres of vertical displacement. GPR acquisition and data processing is potentially easy for subsurface analysis; however this kind of investigation is highly constrained by the overhead wave reflections in complex ge- ological structures, clay-rich material, and the presence of roots in the soils. Consequently, using GPR techniques remains difficult in these environmental conditions and few studies in complex hydro-geological context have been successful. This is the reason why our analysis focuses on the upslope part of the landslides along the road, where a good signal-to-noise was possible because of the road pavement structure. For the moment, no borehole data are available along the GPR cross sections to calibrate the reflector interpretation. Nevertheless, the results of our study show that this field configuration is adequate for using radar pulses to take images of the subsurface and that GPR observations can be used as complementary tool for analysing landslide dynamics.

Acknowledgements. This research was funded by the ANR RiskNat project SISCA: Système intégré de Surveillance de Crises de glissements de terrain argileux (2009-2013) of the Agence Nationale de la Recherche (ANR-08-RISK-0009) and the Project CPER GR2TC: Gestion des Ressources, Risques et Technologie du domaine Côtier (2007-2013). The permanent GNSS system and the automated processing of the observations were set up by the OMIV-EOST Unit at University of Strasbourg as part of the French Observatory on Landslide. We also thank the LETG-Caen Geophen laboratory team for installing the device in the field.

Edited by: A. Günther

Reviewed by: T. M. Fernandez-Steeger and one anonymous referee 


\section{References}

Annan, A. P.: GPR methods for hydrogeological studies, in: Hydrogeophysics, edited by: Rubin, Y. and Hubbard, S. S., Water and Science Technology Library, Springer, the Netherlands, 185213, 2005.

Baldi, P., Cenni, N., Fabris, M., and Zanutta, A.: Kinematics of a landslide derived from archival photogrammetry and GPS data, Geomorphology, 102, 435-444, 2008.

Ballais, J.-L., Maquaire, O., and Ballais, H.: Esquisse d'une histoire des mouvements de terrain dans le Calvados depuis 2 siècles, in: Actes du Colloque "Mouvements de terrain", Documents du BRGM, 83, BRGM, Orléans, 476-483, 1984.

Bichler, A., Bobrowsky, P., Best, M., Douma, M., Hunter, J., Calvert, T., and Burns, R.: Three-dimensional mapping of a landslide using a multi-geophysical approach: the Quesnel Forks landslide, Landslide, 1, 29-40, 2004.

Carpentier, S., Konz, M., Fischer, R., Anagnostopoulos, G., Meusburger, K., and Schoeck, K.: Geophysical imaging of shallow subsurface topography and its implication for shallow landslide susceptibility in the Urseren Valley, Switzerland, J. Appl. Geophys., 83, 46-56, 2012.

Coltorti, M., Dramis, F., Gentili, B., Pambianchi, G., Crescenti, U., and Sorriso-Valvo, M.: The December 1982 Ancona landslide: A case of deep-seated gravitational slope deformation evolving at unsteady rate, Z. Geomorphol., 29, 335-345, 1985.

Deparis, J., Garambois, S., and Hantz, D.: On the potential of Ground Penetrating Radar to help rock fall hazard assessment: A case study of a limestone slab, Gorges de la Bourne (French Alps), Eng. Geol., 94, 89-102, 2007.

Flageollet, J.-C., Gigot, P., Helluin, E., and Maquaire, O.: Studies on landslides in Normandy (France) in view of their occurrence probability, in: Proceedings of the 5th International Conference and Field Workshop on Landslides, ANZSLIDE 87, Australia and New Zealand, Christchurch, New Zealand, 225-233, 1987.

Grandjean, G., Gourry, J.-C., and Bitri, A.: Evaluation of GPR techniques for civil-engineering applications study on a test site, J. Appl. Geophys., 45, 141-156, 2000.

Gutierrez, F., Galve, J. P., Lucha, P., Castañeda, C., Bonachea, J., and Guerrero, J.: Integrating geomorphological mapping trenching InSAR and GPR for the identification and characterization of sinkholes. A review and application in the mantled evaporite karst of the Ebro Valley (NE Spain), Geomorphology, 104, 144156, 2011.

Jeannin, M., Garambois, S., Jongmans, D., and Grégoire, C.: Multiconfiguration GPR measurements for geometric fracture characterization in limestone cliffs (Alps), Geophysics, 71, B85-B92, 2006.
Jol, H. M.: Ground penetrating radar theory and applications, Elsevier, Amsterdam, the Netherlands, 2009.

Lissak, C.: Coastal landslides of the Pays d'Auge (Calvados): Morphology, functioning and risk management, $\mathrm{PhD}$ Thesis, University of Caen, Caen, France, 312 pp., 2012.

Lissak, C., Puissant, A., Maquaire, O., and Malet, J.-P.: Analyse spatio-temporelle de glissements de terrain littoraux par l'exploitation de données géospatiales multi-sources, Revue Internationale de Géomatique, 23, 199-225, 2013.

Lissak, C., Maquaire, O., and Malet, J.-P.: Piezometric thresholds for triggering landslides along the Normandy coast, France/Seuils piézométriques pour le déclenchement de glissements de terrain sur les versants côtiers normands, France, Géomorphologie: Relief, Processus, Environnement, 2, 145-158, 2014a.

Lissak, C., Maquaire, O., Malet, J.-P., Bitri, A., Samyn, K., Grandjean, G., Bourdeau, C., Reiffsteck, P., and Davidson, R.: Airborne and ground-based data sources for characterizing the morphostructure of a coastal landslide, Geomorphology, 217, 140-151, 2014b.

Malet, J.-P., Maquaire, O., and Calais, E.: The use of Global Positioning System techniques for the continuous monitoring of landslides: application to the Super-Sauze earthflow (Alpes-deHaute-Provence, France), Geomorphology, 43, 33-54, 2002.

Maquaire, O.: Les mouvements de terrain de la côte du Calvados: recherches et prévention, Documents du BRGM, BRGM, 197, Orléans, France, 1990.

Neal, A.: Ground-penetrating radar and its use in sedimentology: principles, problems and progress, Earth-Sci. Rev., 66, 261-330, 2004.

Sandmeier, R.: Reflexw Help Notes, Sandmeier Software, available at: http://www.sandmeier-geo.de (last access: December 2014), 1997.

Sass, O., Bell, R., and Glade, T.: Comparison of GPR, 2D-resistivity and traditional techniques for the subsurface exploration of the Oschingen landslide, Swabian Alb Germany, Geomorphology, 93, 89-103, 2008.

Travelletti, J., Delacourt, C., Allemand, P., Malet, J.-P., Schmittbuhl, J., Toussaint, R., and Bastard, M.: Correlation of multitemporal ground-based optical images for landslide monitoring: Application, potential and limitations, ISPRS J. Photogramm., 70, 39-55, 2012.

Tsai, Z.-X., You, G. J.-Y., Lee, H.-Y., and Chiu, Y.-J.: Use of a total station to monitor post-failure sediment yields in landslide sites of the Shihmen reservoir watershed, Taiwan, Geomorphology, 139-140, 438-451, 2012. 